\title{
A rare case of facial palsy caused by Tuberculosis in 1 month old infant
}

\author{
Nathani AA ${ }^{1}$, Rabindran ${ }^{2}$, Parakh $\mathbf{H}^{3}$ \\ ${ }^{1}$ Dr Arif Aziz Nathani, Professor of Pediatrics, Dr VRK Women Medical College, Hyderabad, ${ }^{2}$ Dr.Rabindran, Consultant \\ Neonatologist, ${ }^{3}$ Dr. Hemant Parakh, Consultant Neonatologist. Both are affiliated with Sunrise Superspeciality Children's \\ Hospital, Hyderabad, India
}

Address for Correspondence: Dr Rabindran, E mail: rabindranindia @ yahoo.co.in

\begin{abstract}
Tuberculous presenting in early infancy is rare. Most expectant mothers with TB are asymptomatic \& were discovered to have tuberculosis only after the diagnosis in their infant was made. We report an infant who presented with fever, Right sided cervical mass with ipsilateral LMN type facial palsy with ear discharge whose evaluation revealed Tuberculous. This report describes probably the youngest infant to be diagnosed with cervical mass of tuberculous origin presenting with facial paralysis.
\end{abstract}

Key words: Tuberculosis in infants, Lymphadenopathy, Facial Palsy.

\section{Introduction}

One-third of the world's population and approximately $50 \%$ of Indian adults are infected with Mycobacterium tuberculosis [1]. Despite the high prevalence of TB in women of child-bearing age in India, very few cases of TB in the neonatal period have been reported $[2,3]$. There are about 300 reports worldwide, including 11 from India $[3,4]$. We report an infant who presented with fever, Right sided cervical mass with ipsilateral LMN type facial palsy with ear discharge who did not respond to broad-spectrum antibiotics. On evaluation Tuberculosis was diagnosed.

\section{Case}

A 1 month old baby girl weighing $2.51 \mathrm{~kg}$ presented with history of fever for 4 days with swelling over neck below right ear lobe \& sero-purulent discharge of right ear. Baby was on direct breast feeds. On examination she had enlarged, matted, firm, nontender cervical lymph nodes over right side with right sided LMN type facial palsy. Baby had received BCG vaccination. Chest auscultation revealed bilateral rales and the liver was palpated $3 \mathrm{~cm}$ below the right costal margin. Her CRP was high \& blood culture was sterile. She was started on intravenous antibiotics. She did not respond to the above management \& her septic parameters remained abnormal. USG neck showed 3 round hypoechoic lesions below the right ear suggestive of lymphadenitis. FNAC of lymph node showed plenty of neutrophils, clusters of small lymphocytes \& few macrophages with fibrous tangles suggestive of acute suppurative lymphadenitis. CT head \& neck was normal. CSF analysis was normal. Histopathology examination of right cervical lymph node showed multiple epitheloid granulomas \& langhan's type giant cells with focal fusion \& focal areas of granular acidophilic necrosis. There were patchy lymphoplasmacytic infiltrates around the granulomas suggestive of granulomatous lymphadenitis with caseation necrosis, probably of KOCH's etiology. AFB stain was positive for acid fast bacilli. In view of Koch's occurrence at 1 month of age, flow cytometry nephelometry was done which showed lower values of CD counts; absolute CD3 1534 [normal 3500-5000/microL]; absolute CD4 1237 [normal 2800-3900/microL], absolute CD8 286 [normal $350-2500]$. Immunoassay showed serum non-reactive to HIV I \& HIV II antibodies. Investigation of the mother was suggestive of tuberculous meningitis. Contact-tracing found no other family members with tuberculosis. Antituberculosis chemotherapy with isoniazid, rifampicin, pyrazinamide and ethambutol was commenced in the infant and mother and at follow-up both were in good health. However the facial palsy has not improved 


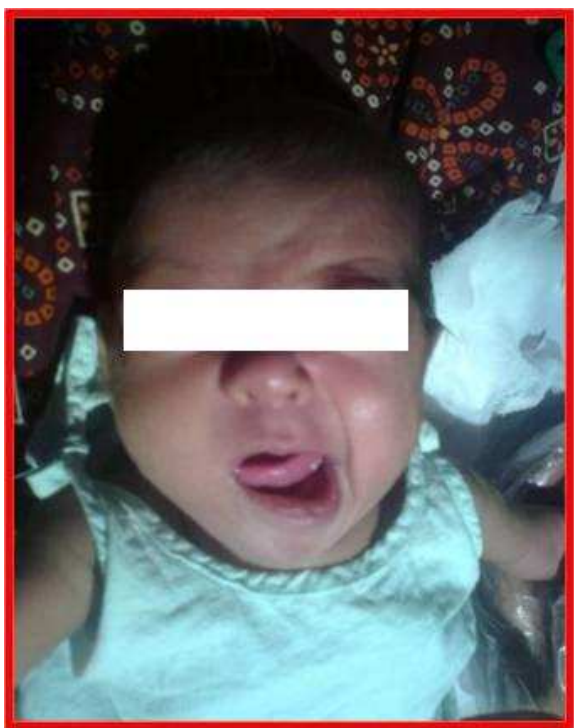

Figure 6: Baby on Admission

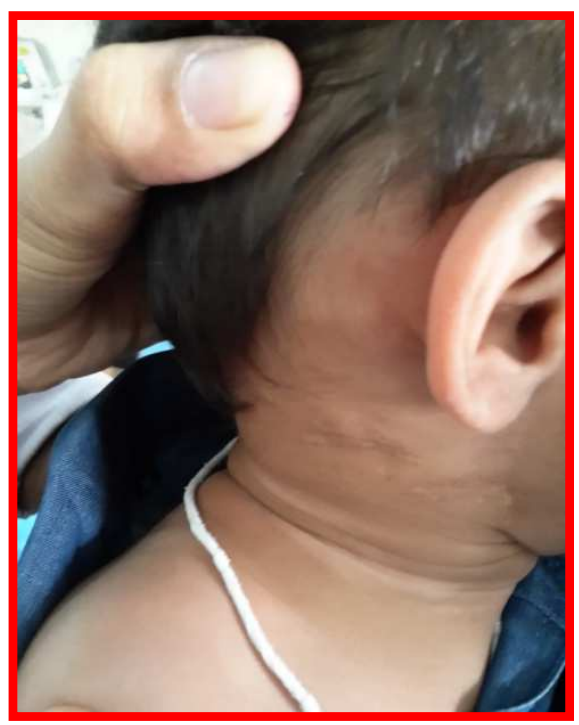

Figure 3: Cervical Scar

\section{Discussion}

TB infection should be considered in all infants with refractory sepsis [5], pneumonia unresponsive to standard treatment and congenital viral infections [6]. Most expectant mothers (nearly 60\%) with TB are asymptomatic [7] and the diagnosis is often missed during pregnancy \& was discovered to have tuberculosis only after the diagnosis in the infants was made as in our case. Although the reported incidence of Neonatal TB is low [8], it is generally a serious condition with a mortality rate of $22 \%$ despite treatment $[3,9,10]$. The clinical presentation of neonatal tuberculosis has a peak onset three to four weeks after delivery but has been reported during the first week of life [7].

Aural discharge as a presenting sign of tuberculosis in early infancy has been reported $[11,12,13]$ as in our case with presentation of right sided sero-purulent discharge.

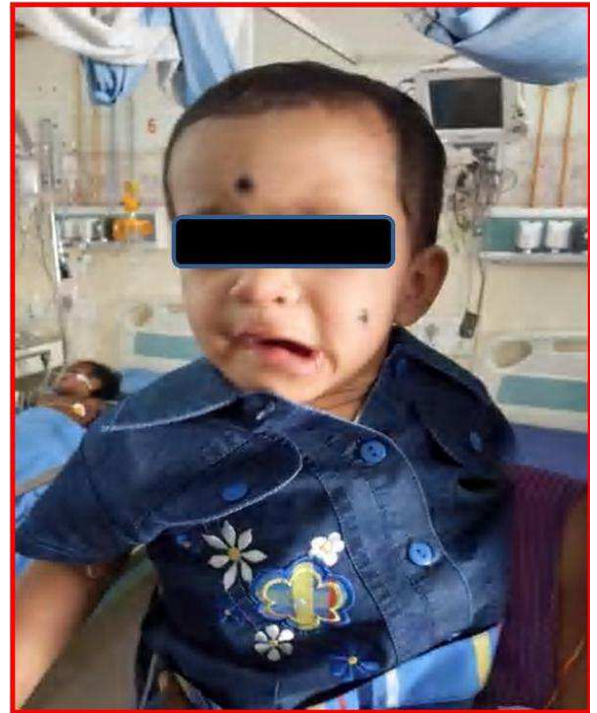

Figure 2: Baby on Follow Up 
1. Raviglione MC, Snider DE, Kochi A. Global epidemiology of tuberculosis. Morbidity and mortality of a worldwide epidemic. JAMA. 1995 Jan 18;273(3):220-6.

2. Balasubramanian S, Shivram R, Padmasani LN, Nagaraju. Congenital tuberculosis. Indian J Pediatr 1999; Jan-Feb 66(1):148-50.

3. Cantwell MF, Shehab ZM, Costello AM, Sands L, Green WF, Ewing EP Jr, Valway SE, Onorato IM. Brief report: congenital tuberculosis. N Engl J Med 1994 Apr ; 330(4):1051-4.

4. Kumar R, Gupta N, Sabharwal A, Shalini. Congenital tuberculosis. Indian J Pediatr. 2005 Jul;72(7):631-3.

5. Mazade MA, Evans EM, Starke JR, Correa AG. Congenital tuberculosis presenting as sepsis syndrome: case report and review of the literature. Pediatr Infect Dis J. 2001 Apr;20(4):439-42.

6. Smith CK. Congenital tuberculosis: a rare manifestation of a common infection. Curr Opin Infect Dis 2002 Jun ; 15(3):269-74.

\section{Case Report}

7. Hageman J.. Shulman S., Schreiber M., Luck S., Yogev R. Congenital tuberculosis: Critical reappraisal of clinical findings and diagnostic procedures. Pediatrics. 1980 Dec;66(6):980-4.

8. Hudson FP. Clinical aspects of congenital tuberculosis. Arch Dis Child 1956 Apr ;31(156):136-9.

9. Ray M, Dixit A, Vaipei K, Singhi PD. Congenital tuberculosis. Indian Pediatr. 2002 Dec;39(12):1167-8.

10. Zheng, Guanghui Bai, Hailin Zhang. Congenital tuberculosis detected by T-SPOT.TB assay in a male infant after in vitro fertilization and followed up with radiography. Italian Journal of Pediatrics 2014 40:96. doi:10.1186/s13052-014-0096-0

11. MacAdam AM, Rubio T. Tuberculous otomastoiditis in children. Am J Dis Child 1977 Feb ;131(2) :152-6.

12. Buchanan G, Rainer EH. Tuberculous mastoiditis. J Laryngol Otol. 1988 May;102(5):440-6.

13. Skolnik PR, Nadol JB Jr, Sullivan B. Tuberculosis of the middle ear. Review of the literature with an instructive case report. Rev Infect Dis. 1986 May-Jun;8(3):403-10.

\section{How to cite this article?}

Nathani AA, Rabindran, Parakh H. A rare case of facial palsy caused by Tuberculosis in 1 month old infant . Int J Med Res Rev 2015;3(4):441-443. doi: 10.17511/ijmrr.2015.i4.077. 